\title{
The real estate industry and economic development issues discussed
}

\author{
Zhi.Neng. TONG \\ Jiangxi science \& technology normal university China
}

\begin{abstract}
KEYWORD: Real estate; Urbanization; Economic development; Cycle
ABSTRACT: Through the course of the economic cycle and the development of urban real estate industry analysis process, economic development, in-depth study of the real estate cycle fluctuations and macroeconomic volatility relationship, trying to figure out the development of the real estate cycle and links between the current economic city fluctuations in the real estate cycle process development law issues to try to do some qualitative research.
\end{abstract}

\section{INTRODUCTION}

In the past decade, urbanization and real estate development in China a golden opportunity in the process to expand the scale of the special situation during the process of China's urbanization, real estate development debate.

So much controversy to the long-term development of the real estate industry have a profound impact on the adjustment of national policies, urbanization, construction and real estate related to urbanization. Short-term and long-term industrial development, which points to different areas and at different stages. If the same yardstick to measure different periods, at this stage, the speed and structure of the region is prone to bias. The underlying trend in real estate development in China's urbanization process, the long-term trend, it should be in the context of economic development, economic fluctuations periodic intervals grasp urbanization and real estatesituation observed from the general, global, in nature.

In economics, the economic cycle is repeated alternately alternately economy, recession, recovery, rising prosperity, crisis, recession process and the rule of law in the process of expansion and contraction of the operation. Therefore, the corresponding increase in the real estate business cycle is the iterative process of running real estate expansion and contraction of economic prosperity and decline of the movement and the drop in the process of de facto constantly changing reciprocation. In one cycle, the real estate economy, can be divided into rising (prosperity) and decline phase (recession) of two stages, rising from trough to peak, from peak to trough decline phase.

Real estate boom and bust cycle, fluctuations in prosperity and recession, interconnected in a week, so that fluctuations in the cycle back and forth. Fluctuations in real estate, including changes in the rate of economic growth of real estate property in the course of the level of consumption levels, employment, the level of the real estate industry, real estate price levels, urbanization and industrial structure.

\section{REAL ESTATE DEVELOPMENT AND THE RELATIONSHIP BETWEEN THE ECONOMIC CYCLE}

Morphological sense, the expansion of urban construction, urbanization is real estate oriented. Essence of the history of the real estate industry is the history of urbanization. (Live) transformation of the city urbanization, agricultural resources and agricultural production activities and rural residents. Fluctuations in the economic cycle urbanization construction and real estate development cycle theory can not explain? In Western industrialized countries, urbanization history has proven, it describes the period of economic fluctuation theory coincided. In fact, this may not be a coincidence, because the development of urbanization are associated with recession and prosperity of the real estate industry related to the conversion of the economic cycle at any time.

Although up to now has not been established for the real estate industry in the process of urbanization in the theoretical framework of a volatile period, but the draw the fluctuation period theory can be found, a development in a period of rapid urbanization process will not be unlimited, 
real estateperiod maintain its high growth momentum, with the fluctuations of the economic development, it will self-adjust their pace of development, that is sometimes fast, sometimes slow and consistent economic development cycle, again and again, eventually to be replaced by new growth. This is mainly due to the result of the fluctuation cycle of the dominant real estate capital goods. From an economic sense, the growth of the national economy is the urbanization process boils down building activities, the urbanization construction activities cycle around fluctuations in the cycle of economic trends and fluctuations, investment fluctuations often seen as a development of the urbanization process in the real estate cycleengine. The fluctuations of the investment is the urban fixed asset investment in the output of capital goods, most clearly reflected on the valueadded of the three elements of the infrastructure, land and population, is referred to as a city body three basic power, these three the major driving force is the most indicative of the the urbanization variable model of growth and recession in the real estate industry. These three elements according to the different types of investment activities, to produce capital goods cycle length. In actual operation, only when all three variables between the formation of an optimal balance point, the urbanization construction activities in some optimal combination will produce real estate explosive boom period. Here, the combination of three elements fluctuations is a key turning point in urbanization in developing real estate boom and bust.

The land is a resource for the city, for the production and the basic needs of life, it is proportional to the demand and the price of land. When urban construction in the rising phase of a prelude, the performance is land scarcity, the apparent growth in demand, the price of this period the highest proportion, land cycle peaks. However, the land as a resource, its demand will fluctuate with the national economy, urban land can not expand infinitely, and most of the time total in a balanced growth path to reach a fixed form of limits to growth. So, the increment of land in the real estate industry is not better, it is determined by economic laws, is a good grasp of cycle timing to maximize the effectiveness of limited land, to avoid the substantial investment in invalid citythe scale of the real estate industry.

Mainly on demographic change and urbanization, the real estate development, the rate of growth of employment relations. Early urbanization, the manufacturing sector accounted for the absolute advantage of the city, the urban employed population and manufacturing almost simultaneously. Urbanization highly developed late, the source of urban employment is no longer bound by agriculture, manufacturing out of the city to be replaced by the third, fourth industry and source of employment for changes to flow between cities, population transfer from one city to another city, population growth in employment became the urbanization process in the real estate revival and prosperity means.

\section{URBANIZATION PROCESS AS IN THE REAL ESTATE DEVELOPMENT CYCLE}

China's urbanization process of real estate development cycle it exists? The answer is yes. First, the theoretical understanding the fluctuation cycle theory of universal significance. Currently, the fluctuation cycle theory Western economists accepted real estate industry is part of the economic development in the process of urbanization, naturally need to be constrained by economic fluctuations in the development cycle, this is no doubt. Mutual relationship between economic development and urbanization, the real estate development work, real estate is not just passively benefit from economic growth, and we have prepared the preconditions. The problem is the condition of the real estate development in China's urbanization process, in many ways different from 18, the 19th century in Europe and the United States, combined with the urbanization of the western countries are the ideal model of capitalist development, and China should follow is the development road of urbanization with Chinese characteristics. Therefore, this issue does have many different views. However, we should also see that the historical development always have its common regularity. Business Cycle theory is a historical analysis of the economic development of any country for any period, the focus is to find the basic situation of regularity something similar under the historical process. Spoke today about the Western developed countries, the industrialized countries, which means that industrial society is the prototype of the modern developed society, 
urbanization, industrialization burst out we discuss the common basis of the development of urbanization. History, the European countries in the process of urbanization is also very different, but if we put these countries urbanization process as a whole, to be taken into account in general, is not difficult to find, the city towards modern social processes always have asome of the general trend of the trajectory appear. So, to say that the the fluctuation cycle theory, scientific research and development trends, rather than to predict the future number of computational science.

Second, the formation mechanism from the cycle of view, the process of urbanization, the development of the real estate industry has similar conditions with the economic cycle mechanism, it also has intrinsic conduction mechanisms and characteristics of the external shock mechanism. External shocks, including major institutional changes, policy guidance, and the sudden impact and other factors, the initial cause of cyclical fluctuations, less this we can not form a cycle fluctuations. Intrinsic conduction mechanism: the accelerator mechanism, land population and infrastructure associated mechanism, the upper limit lower limit of the buffer mechanism. Intrinsic conduction mechanism reflects the effect of the structure of the inner city, mainly through variable associated structural parameters reflected, play a role in the impact of self and self-adjustment.

\section{CONCLUSION}

Real estate development in the urban construction in China has been promoting the urban economy as a marginal scientific research, emphasizing the overall combination of urban economic, social, technical internal factors, but over the years with little success. Western countries Cycle Research Institute reflect the purpose is clear cycle theory of fluctuations in the economy to focus on longterm strategy for economic growth of a country or region, and the use of the means of policy measures to adjust the wave guide crest ahead of the arrival or postpone the emergence of the trough, which limit the negative effects of the economy. Chinese urban real estate, such as to strengthen the combination with fluctuations in the economy cycle, we must learn from the rule of the Business Cycle theory, to reveal the mechanism of the cyclical fluctuations in the real estate industry in urban development, the rich urban construction, real estate development in order to research and solve the city fluctuations in unified pace of construction, real estate and economic development issues, and guide the process of urbanization in the real estate of the sustained, healthy and orderly development; avoid blind expansion and abuse built urbanization works in real estate development and serious bubble and waste of resources.

This article is a brief overview of the theory of fluctuations in the economy cycle mechanism, just borrow the assumptions of the theory of fluctuations in the economic cycle, led to explore the urban construction in the urbanization process, the idea of the relationship between the economic theory of the real estate development and volatility cycle, did not involves quantitative analysis, but I hope that the above problems of the interest of scholars and policy makers, can cause further to do indepth quantitative calculation, reference and basis for the health of the real estate industry in the process of urbanization, the long-term, orderly development.

\section{REFERENCE}

1.Wu ShuLian, Study on the relationship between the city and the real estate industry interaction development. Enterprise management press,2009

2.Tan Gang, Fluctuations in the real estate cycle. Economic Management Press, 2001

3.Guo JinXing, The virtual and the fluctuation of real estate, NanKai University Press, 2005

4. Qu Bo, Real Estate Economic Fluctuations Theoretical and Empirical Analysis, China Land Press. 